\title{
Fabrication of anti-vitiligo ointment containing Psoralea corylifolia: in vitro and in vivo characterization
}

This article was published in the following Dove Press journal:

Drug Design, Development and Therapy

22 November 2016

Number of times this article has been viewed

\author{
Irshad Hussain ${ }^{1,2}$ \\ Nisar Hussain ${ }^{3}$ \\ Abdul Manan ${ }^{1,2}$ \\ Abdur Rashid ${ }^{4}$ \\ Barkat Khan ${ }^{5}$ \\ Sattar Bakhsh ${ }^{5}$ \\ 'Department of Dermatology, \\ ${ }^{2}$ Department of Pharmacy, SMBB \\ Medical University, Larkana, ${ }^{3}$ Faculty \\ of Pharmacy, Bahauddin Zakariya \\ University, Multan, ${ }^{4}$ Drug Regulatory \\ Authority of Pakistan, Islamabad, \\ ${ }^{5}$ Faculty of Pharmacy, Gomal \\ University, D.I.Khan, Pakistan
}

Background: Vitiligo is a repugnant and odious dermatological malady of the time. It has an detrimental impact on the pigmentation of the human skin as a result of the destruction of cutaneous melanocytes. It affects $1 \%-2 \%$ of the population worldwide. Different therapeutic regimens have been deployed to treat vitiligo, but none of them could stand alone to be stated as a perfect cure. Recently, a change has been observed through novel experimental-designed optimization leading to the development of an anti-vitiligo ointment containing Psoralea corylifolia (PC) seed powder.

Aim: The aim of this study was to explore the clinical outcomes of ointment containing powdered seeds of PC.

Materials and methods: Guided by the protocol Response Surface Methodology, 13 formulations of concentration variance of permeation enhancers were prepared. The formulation fulfilling the required criteria $\left(\mathrm{pH}\right.$; temperature stability tests at $8^{\circ} \mathrm{C} \pm 0.1^{\circ} \mathrm{C}, 25^{\circ} \mathrm{C} \pm 0.1^{\circ} \mathrm{C}$ and $40^{\circ} \mathrm{C} \pm 0.1^{\circ} \mathrm{C}$; and the physical properties such as color, bleeding and rheology) was selected for clinical trials. Fourier transform infrared spectroscopy studies of seed powder of PC and selected formulation of the seed powder were performed. After obtaining informed consents and with prior approval of university and hospital ethical review boards, 20 patients (age range 25-65 years) were included in the present study. Formulations were applied on the affected body parts of patients, and some affected portion of the same patient was taken as control (self-control study design). The pigmentation of white spots of vitiligo was photographically evaluated before, during and after 12 weeks of treatment. Analysis of the measured values was performed using GraphPad Prism version 5 statistical software. A paired sample $t$-test was performed to observe variation between repigmented patches and white patches of self-control.

Results: Hydrophilic ointment (10\% w/w) prepared with seed powder of PC was fabricated. The ointment was found effective for small circular white lesions of vitiligo as compared to self-control. Pre- and post-treatment differences in the levels of pigmentation were statistically significant $(P \leq 0.05)$.

Conclusion: Ointment containing seed powder of PC could be an effective monotherapy for small circular white lesions of vitiligo.

Keywords: vitiligo, leucoderma, Psoralea corylifolia, PC, puva, novel design optimization, babchi, anti-vitiligo ointment

\section{Introduction}

Vitiligo is an repugnant and odious malady of the time. It has an detrimental impact on the pigmentation of human skin as a result of the destruction of cutaneous melanocytes and affects $1 \%-2 \%$ of the population worldwide. ${ }^{1}$ The disease is acquired, idiopathic,
Correspondence: Irshad Hussain I Doctors St, Mauza Mannaha Sharief, Kot Addu - 34050, Punjab, Pakistan Mobile +92 31 272 I4II2

Email irshadpharmacist@yahoo.com (c) (1) \& 2016 Hussain et al. This work is published and licensed by Dove Medical Press Limited. The full terms of this license are available at https://www.dovepress.com/terms.php cc. hereby accept the Terms. Non-commercial uses of the work are permitted without any further permission from Dove Medical Press Limited, provided the work is properly atributed. For permission for commercial use of this work, please see paragraphs 4.2 and 5 of our Terms (htpps//www.dovepress.com/terms.php). 
circumscribed depigmentation of skin characterized by distinct white lesions, often connected with a positive family history. ${ }^{2}$ Its prevalence is almost uniform among the entire human population, and its far-reaching impact is more conspicuous in dark-skinned peoples. As white patches of vitiligo (being nearly identical to normal white skin) are rendered less prominent in white populations, apparently these populations are least affected..$^{3,4}$ Vitiligo can depigment any of the body organs, which may vary from case to case. Though, definite etiopathogenic mechanisms of vitiligo are undecided, however, based on indirect evidence, some hypotheses suggest a strong linkage as contributing factors such as autoimmune, genetic, oxidative stress, melatonin receptor dysfunction and impaired neural and viral dermatological pathology. Some investigators are also of the view that skin around the lesion of vitiligo may represent the underlying substance where death of melanocytes is evident. These dead melanocytes may further pave a key role in the progression of vitiligo. ${ }^{5}$ SIRT1 modulates MAPK pathway via Akt-apoptosis signalregulating kinase-1 and negatively regulates pro-apoptotic substances, resulting in reduction of oxidative stress and apoptotic cell damage of keratinocytes of perilesional skin. ${ }^{6}$ Moreover, in vitiligo-induced cell-mediated immunity, it has been demonstrated that the prime role is manifested by potentiated Th1 and Th17 and by inhibition of Tregs and Th2 lymphocytes. Specifically, low-dose therapy with activated cytokines and bFGF could have a beneficial effect on redox microenvironment in the melanic epidermal units and thus may be considered as a targeted therapy for vitiligo. ${ }^{7}$ Vitiligo may be categorized as non-segmental (symmetrical patches) or segmental (asymmetrical patches) ${ }^{8}$ Various psychological complications have been observed and recorded in the patients. The ailment is considered as erroneous stigmatization that can even influence the likelihood of marriages. ${ }^{4}$ Currently, vitiligo is managed by three distinct ways, ie, cosmetics, therapeutic and surgical. A few advancements, in achieving the therapeutic goals, have been cited in the literature over the past two decades. In this context, different therapeutic regimens have been deployed to treat vitiligo, but none of them could stand alone to be declared as a perfect cure. ${ }^{9}$ Psoralea corylifolia (PC) of family Fabaceae also called babchi in local dialect is an important medicinal plant. It is indigenous of India, Bangladesh and Sri Lanka. Its medicinal uses have been reported in British, Chinese, Indian and American pharmacopeias in the traditional system of medicines of Siddha, Ayurveda and Unani. ${ }^{10}$ The powdered seed of the plant has characteristic fragrance and is well known in the region as "Kasturi" (deer musk), especially in Bengali language. ${ }^{11}$
The dried mature seeds contain furocoumarins from which psoralens are derived. ${ }^{12}$ These are the products that have been utilized as a treatment of vitiligo, leprosy and psoriasis since ancient ages. ${ }^{13}$ The constituents from PC also exhibit the antimicrobial characteristics. Researchers discussed the three antibacterial structures for their structure-activity relationship. ${ }^{14}$ The ointment is semisolid topical preparation, applied with little rubbing and prepared either by fusion or trituration methods. The ointment containing water in its composition is termed as hydrophilic ointment. It serves as a base for the topical treatment. ${ }^{15}$

\section{Materials and methods}

\section{Plant materials and preparation of plant powder}

Dried vigorous seeds of PC were purchased from Kaoromul Supplier, Larkana, Pakistan and were identified by a botanist Khawaja Asad Abbas of Sadiq Egerton College, Bahawalpur, Pakistan. The seeds were thoroughly washed with running tap water, followed by distilled water, and then air-dried. These were powdered well using mechanical grinder and passed through the sieve 200 to get a fine powder. The powdered material was weighed, kept in an airtight container and stored in the refrigerator for further studies.

\section{Chemicals}

The chemicals used were methylparaben, propylparaben, olive oil (OO), propylene glycol (PG), stearyl alcohol and white petrolatum.

\section{Phytochemical screening}

Phytochemical screening of the powder form was performed for flavonoids, tannins, phenoles, saponins, carbohydrates, alkaloids, coumarins and psoralens. Preliminary phytochemical analysis was performed in accordance with standard protocols ${ }^{16}$ detailed as follows.

\section{Test for flavonoids}

About $1 \mathrm{~g}$ of plant seed powder was washed with ether to set it free from fatty substances. The residue was dissolved in $30 \mathrm{~mL}$ of $80 \%$ ethanol and subjected to filtration. The filtrate $(3 \mathrm{~mL})$ was mixed with $1 \%$ aluminum chloride $(4 \mathrm{~mL}$ prepared in ethanol).

\section{Test for tannins}

In all, $0.25 \mathrm{mg}$ of plant seed powder was dissolved in $5 \mathrm{~mL}$ of distilled water. Then, it was filtered, and two to three drops of ferric chloride (1\%) solution were added in it. 
In another similar technique, plant seed powder was dissolved in gelatin solution ( $1 \%$ ) containing sodium chloride.

\section{Test for phenol}

A few drops of 5\% neutral solution of ferric chloride were added to $1 \mathrm{~mL}$ of aliquot of plant powder.

\section{Test for cardiac glycoside}

A few milliliters of concentrated sulfuric acid were added to $500 \mathrm{mg}$ of plant seed powder and boiled, cooled and neutralized (with $20 \%$ potassium hydroxide). Then, ferric chloride solution was added to it.

Test for anthraquinone glycosides (Borntrager's test) Dilute sulfuric acid (few drops) was added to plant seed powder $(1 \mathrm{~g})$. Then, the mixture was boiled and filtered. The filtrate was extracted by chloroform. The chloroform layer was separated and treated with ammonia $(1 \mathrm{~mL})$.

\section{Frothing test for saponins}

Frothing test, an indicative of saponins, was performed in a simple procedure. Plant seed powder (500 mg) was added to distilled water in a test tube and then boiled and cooled. The test tube was shaken vigorously to see frothing pattern to classify saponins in one of the three categories as listed as follows:

1. no froth: no saponins;

2. froth $<1 \mathrm{~cm}$ : weakly positive;

3. froth $>1 \mathrm{~cm}$ : positive test, and

4. froth $>2 \mathrm{~cm}$ : strongly positive.

\section{Test for carbohydrates}

In all, $500 \mathrm{mg}$ of the extract was dissolved in $2.5 \mathrm{~mL}$ of distilled water, and the solution was filtered. The filtrate (1 mL) was added:

1. to $5 \mathrm{~mL}$ of Benedict's reagent, heated and cooled (to watch orange red precipitate as indication of reducing sugar) and

2. to $\mathrm{HCl}$ (a few milliliters) and neutralized with alkaline solution and heated with Fehling's solutions A and B (to observe red precipitate, an indication of reducing sugar).

\section{Tests for alkaloids}

Dragendorff's test

Plant seed powder $(5 \mathrm{~g})$, after stirring with $\mathrm{HCl}(5 \mathrm{~mL})$, was heated on a water bath and filtered. The filtrate $(1 \mathrm{~mL})$ was used to identify alkaloids by mixing with Dragendorff's reagent $(1 \mathrm{~mL})$.

\section{Wagner's test}

The filtrate $(1 \mathrm{~mL})$ was used to identify alkaloids by mixing with Wagner's reagent $(2 \mathrm{~mL})$.

\section{Tests for coumarins}

A filter paper (moistened with sodium hydroxide) was kept over the test tube containing boiling plant extract.

\section{Tests for psoralens}

The following were the tests carried out for psoralens:

1. Plant seed powder was dissolved in $5 \mathrm{~mL}$ of ethanol, and a mixture $(15 \mathrm{~mL})$ containing three parts of $\mathrm{PG}$, five parts of acetic acid and 43 parts of water was added.

2. Plant seed powder was dissolved in ethanol $(2 \mathrm{~mL})$ and mixed with sodium hydroxide (two drops). The formed solution was subjected to ultraviolet (UV) light. ${ }^{17}$

\section{Formulation and characterization of ointment}

Hydrophilic ointment was prepared with partial modification of United States Pharmacopoeia (USP). ${ }^{18}$ In the first step, melting of stearyl alcohol and white petrolatum was carried out in a steam bath at $75^{\circ} \mathrm{C}$. The resultant mixture was labeled as mixture 1. Next, methylparaben, propylparaben, $\mathrm{OO}, \mathrm{PG}$ and powdered seeds of PC were dissolved in water and warmed up to $75^{\circ} \mathrm{C}$ in steam bath; the resultant mixture was labeled as mixture 2 . The next step involved was addition of mixture 2 to mixture 1 , and the resultant mixture (labeled as mixture 3) was agitated till it got congealed. The composition of formulation is summarized in Table 1. Thirteen formulations with varying concentrations of permeation enhancer were prepared. PG and SLS were used as permeation enhancer as per protocol of "Response Surface

Table I Composition of I,000 g of hydrophilic ointment containing $10 \% \mathrm{w} / \mathrm{w}$ seed powder of PC

\begin{tabular}{llll}
\hline Serial no & Ingredient & $\mathbf{g}$ & $\%$ \\
\hline 1 & Methylparaben & 0.25 & 0.025 \\
2 & Propylparaben & 0.15 & 0.015 \\
3 & OO & 6 & 0.6 \\
4 & PG & 110 & 11 \\
5 & Stearyl alcohol & 250 & 25 \\
6 & White petrolatum & 250 & 25 \\
7 & Powdered seed (PC) & 100 & 10 \\
8 & Purified water & 283.6 & 28.36 \\
\hline
\end{tabular}

Notes: The procedure for preparation of hydrophilic ointment is as follows:

I. Melt the stearyl alcohol and the white petrolatum on a steam bath and warm to $\sim 75^{\circ} \mathrm{C}$.

2. Add the other ingredients including drug (powder form of PC) previously dissolved in the water, warm to $75^{\circ} \mathrm{C}$ and stir the mixture until it congeals.

3. Preserve the ointment by packaging and storing in tight containers.

Abbreviations: PC, Psoralea corylifolia; OO, olive oil; PG, propylene glycol. 
Methodology" (as enlisted in Table 2). This methodology was deployed to optimize topical formulations. ${ }^{19}$ These formulations were tested against full range of parameters, for instance, $\mathrm{pH}$, temperature stability tests in $8^{\circ} \mathrm{C} \pm 0.1^{\circ} \mathrm{C}$, $25^{\circ} \mathrm{C} \pm 0.1^{\circ} \mathrm{C}$ and $40^{\circ} \mathrm{C} \pm 0.1^{\circ} \mathrm{C}$ and physical properties such as color, bleeding (separation of liquid) and rheology.

\section{Experimental design for the development of formulation}

Central composite design (CCD) of Response Surface Methodology was employed. Amounts of PG $\left(X_{1}\right)$ and SLS $\left(X_{2}\right)$ were selected factors to study at three levels each. Central point $(0,0)$ studies were performed in quintuplicate, keeping all other processing factors unchanged throughout the study period. A sum of total 13 experimental runs and their factor combinations as per chosen experimental design and translation of coded levels in actual units are summarized in Table $2 .{ }^{20}$

\section{Fourier transform infrared spectroscopy (FTIR)}

FTIR is a preferred technique of infrared (IR) spectroscopy. It works on the principle of absorption and transmission of IR radiation when passed through a sample, resulting in molecular absorption and transmission spectrum (molecular fingerprint of sample). Molecular fingerprint is the unique spectrum, specific for specific molecules useful for identification and qualitative and quantitative analyses

Table 2 Factor combination as per chosen experimental design and translation of coded levels in actual units

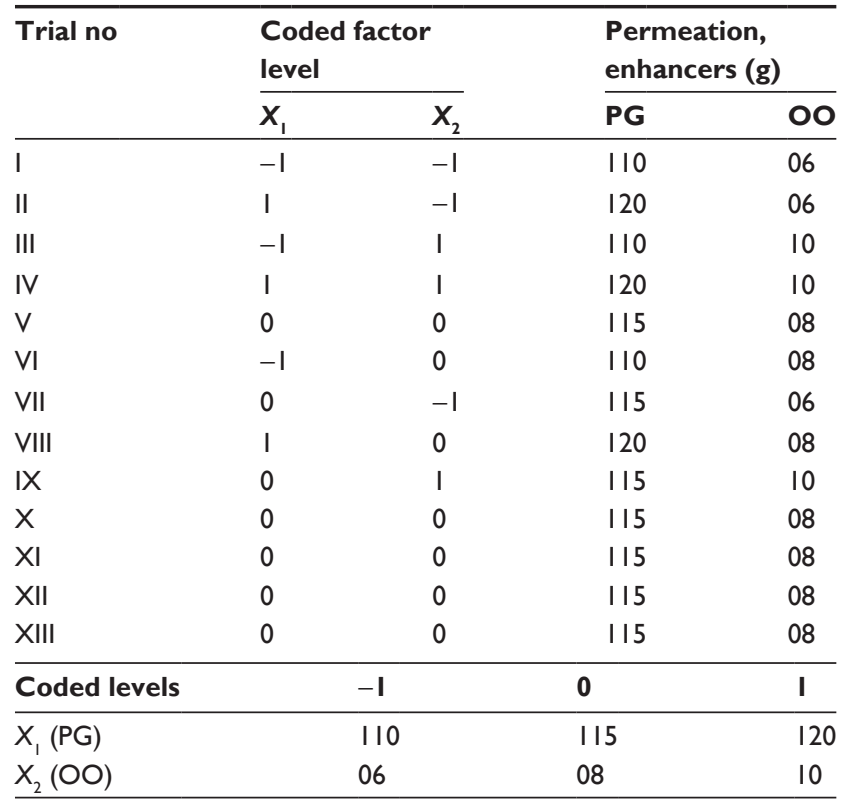

Abbreviations: PG, propylene glycol; OO, olive oil. of sample. ${ }^{21}$ The current study involved the separate FTIR spectroscopy of powdered seeds of PC and selected formulation to know any interaction between powdered drug and other ingredients of formulation. In the first spectroscopic step, spectrum of powdered drug was recorded, while in the second step, the spectrum of formulation was obtained using the FTIR spectrophotometer (RX-I, Lambda; PerkinElmer Inc., Waltham, MA, USA). The scanning of samples was carried out at $4,000-40 \mathrm{~cm}^{-1}$ wave number range. ${ }^{20}$

\section{Antimicrobial assay}

Antimicrobial assay was performed separately for active (methylated extract of powdered form of PC) and formulation.

\section{Subjects}

Twenty prior informed, otherwise healthy, volunteers (age range 18-60 years) were included in the study. The volunteers were asked to apply ointment on the selected white lesions once a day. Additionally, they were instructed to expose the selected white lesions of the skin to sun rays as long as they can tolerate, just after the application of the ointment. ${ }^{21}$ Five volunteers were reported to be moderately irritated with the formulation and were advised to use cream containing betamethasone (counter irritant) twice a day on the affected part of the skin under trial. Volunteers were instructed not to use any other skin product, especially whitening agents throughout the duration of study (12 weeks).

\section{Patch test}

The patch test was performed to know any possible hypersensitivity against the formulation. A 5 -point $(0,1,2,3,4)$ scale was used to quantify the itching or irritation experiences by volunteers with 0 of the scale representing no itching and 4 relatively severe itching or irritation experience.

\section{Study design for clinical trials}

A self-controlled trial (patient serves as own control) was conducted to evaluate the effects of formulations on the improvement of white patches of skin. In the trial setting, each patient served as his/her own control before or after treatment or both. ${ }^{22}$ The formulation was applied with rubbing on the affected body part of the patient, and the same patient was regarded as control for his portion where formulation was not applied.

\section{Ethical considerations}

The ethical committee of Faculty of Pharmacy, Bahauddin Zakariya University, Multan, Pakistan, approved the protocol 
of this study (2319-A/Pharm/2014). Prior to registration, signed informed consent was obtained from the volunteers.

\section{Visual survey}

Reductions in vitiligo white spots were measured in comparison with control and were documented in the form of photographs of specific skin area by using a 20-megapixel camera (DSC-W800/SC, E37; Sony). Photographs of the selected white spots (before and after application of ointment) and control were taken till the completion of the trial period (either after 12 weeks or after full pigmentation of the skin, whichever was earlier).

\section{Statistical analysis}

Statistical analysis of the measured values was performed using a statistical software, ie, SPSS (version 19; IBM Corporation, Armonk, NY, USA) or "GraphPad Prism" (version 5). A paired sample $t$-test was performed to observe central tendencies, variations and deviations between repigmented patches and white patches of self-control. One-way analysis of variance combined with Dunnett's multiple post test was carried out to analyze the correlation between baseline values of observation and the values at uniform interval (12 days). $P$-values $<0.05$ were considered as statistically significant.

\section{Results and discussion Phytochemical screening}

Preliminary phytochemical screening of powdered form of PC proved the existence of flavonoids, tannins, phenols, cardiac glycosides, saponins, alkaloids, psoralens and absence of coumarins and carbohydrates (Table 3).

Test for flavonoids: Dark yellow-colored precipitation was indication of flavonoids.

Table 3 Phytochemical screening of powdered form of PC

\begin{tabular}{ll}
\hline Tests & Results \\
\hline Flavonoids & + \\
Tannins & - \\
Phenols & + \\
Glycosides & + \\
Saponins & + \\
Carbohydrates & - \\
Alkaloids & + \\
Coumarins & - \\
Psoralens & ++ \\
\hline
\end{tabular}

Note: Present $=+$, strongly present $=++$ and absent $=-$. Abbreviation: PC, Psoralea corylifolia.
Test for tannins: No white precipitate referred to absence of tannins.

Test for phenols: Dark green coloration indicated phenols.

Test for cardiac glycoside: Presence of glycosides was indicated by a dark yellow coloration by adding ferric chloride in the solution of extract.

Test for anthraquinone glycosides (Borntrager's test): The reddish color ammonia layer indicated the presence of anthraquinone glycosides.

Frothing test for saponins: The extract was found to be strongly positive for saponins as the resulted froth was $>2 \mathrm{~cm}$.

Test for carbohydrates: The test indicated absence of any carbohydrates (no orange red precipitate with Benedict's reagent and no red precipitate with Fehling's solutions A and B).

Tests for alkaloids: Dragendorff's test.

Orange red precipitate was an indication of alkaloids.

Wagner's test: Reddish brown precipitation was an indication of alkaloids.

Tests for coumarins: No yellow fluorescence of filter paper on exposure to UV light indicated absence of coumarins.

Tests for psoralens: The emitted yellow fluorescence on exposure to UV light indicated psoralens.

Phytochemical screening of extract of PC with different solvents revealed the presence of bioactive compounds such as phenolics, flavonoids, tannins, alkaloids, terpenoids, steroids, carbohydrates, glycosides and proteins. ${ }^{23}$

\section{Formulation and characterization of ointment (hydrophilic ointment)}

Thirteen formulations were tested for stability against $\mathrm{pH}$, temperature and physical properties such as color, odor and bleeding. Rheology of only one formulation was successfully measured by rheometer as remaining formulations failed to run in the rheometer because if its highly viscous nature. Rheological properties of the selected ointment were interpreted as "the increase in share rate decreases viscosity" (Table 4 and Figure 1); therefore, one of the 13 formulations (Table 1) was screened for FTIR studies, antimicrobial assay and its clinical trials on the selected volunteers. It is in vitro perception of in vivo spread ability of ointment that after application on skin, its viscosity will decrease due to shear stress. $^{24}$

\section{Response surface optimization analysis}

CCD involved 13 experimental runs. The values of independent variables ie, $X_{1}(\mathrm{PG})$ and $X_{2}(\mathrm{SLS})$, are presented in 
Table 4 Rheological report of formulated ointment by rheometer

\begin{tabular}{lllllll}
\hline Serial no & Viscosity $(\mathbf{c P})$ & Speed & \% torque & Shear stress $(\mathbf{d y n} / \mathbf{c m})$ & Shear rate $(\mathbf{I} / \mathbf{s e c})$ & Temperature $\left({ }^{\circ} \mathbf{C}\right)$ \\
\hline 1 & 744.17 & 10.00 & 60.63 & 148.83 & 20.00 & 24.33 \\
2 & 671.62 & 13.00 & 71.09 & 174.62 & 26.00 & 24.35 \\
3 & 630.12 & 16.00 & 82.10 & 201.64 & 32.00 & 24.38 \\
4 & 606.24 & 19.00 & 93.82 & 230.37 & 38.00 & 24.38 \\
5 & 570.18 & 22.00 & 110.00 & 250.83 & 54.00 & 24.43 \\
6 & 510.11 & 25.00 & 110.00 & 287.54 & 56.00 & 24.45 \\
7 & 440.35 & 28.00 & 110.00 & 220.92 & 62.00 & 24.45 \\
8 & 380.76 & 31.00 & 110.00 & 219.44 & 68.00 & 24.45 \\
9 & 290.26 & 34.00 & 110.00 & 180.36 & 74.00 & 24.53 \\
10 & 229.34 & 37.00 & 69.14 & 169.71 & 80.00 & 24.50 \\
11 & 200.78 & 40.00 & 65.41 & 160.62 & 86.00 & 24.55 \\
12 & 173.92 & 43.00 & 60.93 & 149.57 & & 24.55 \\
\hline
\end{tabular}

Table 2. Two-dimensional surface and contour plots were studied for response property (viscosity) as presented in Figures 2 and 3. The figures exhibit that changes in the concentration of permeation enhancers influence viscosity (dependent variable) of the formulation; as a result, permeation is affected.

\section{FTIR spectroscopy}

FTIR spectrum of powdered form of PC (Figure 4) and FTIR spectrum of formulation (Figure 5) were observed to be nearly identical without any significant difference in characteristic peaks; thus, the nature of powdered drug remained relatively same after its incorporation in the formulation and the ingredients of formulation were compatible with the drug. Comparison of FTIR spectra of some pure drugs and their formulation has been carried out by other studies. ${ }^{20,25,26}$

\section{Antimicrobial assay}

Streaks of mixed cultures (Gram positive and Gram negative) of bacteria were spread on nutrient agar and MacConkey agar, which resulted in no growth of culture after 24 hours of incubation in the presence of methylated extract of powdered drug. It confirmed the innate antimicrobial

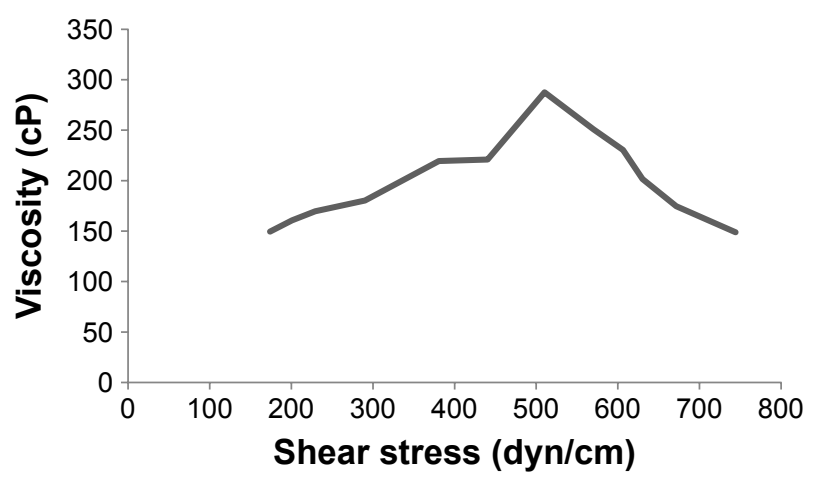

Figure I Effect of increased shear stress on viscosity of formulation. spectrum of the drug. The result also supported the existing data about the antimicrobial potential of PC. ${ }^{26}$ Similar results were obtained when the same antimicrobial assay was repeated for the formulation under the same set of conditions, thus, confirming antimicrobial spectrum of the formulation that possesses the preservatives (methylparaben and propylparaben). Significant and broad-spectrum antibacterial properties were confirmed in the isolated components (psoralen, psoralidin, angelicin, bakuchicin) of PC seeds. ${ }^{27}$ Nine of the 12 isolated constituents from the seeds of PC elucidated significant antibacterial activities against pathogens Staphylococcus aureus and Staphylococcus epidermidis. ${ }^{14}$

\section{Patch test}

Mild irritation of scale-1 level was reported in 15 volunteers, and moderate irritation of scale-2 level was reported by five volunteers. Betamethasone was topically applied along with formulation as counter irritant in patients with moderate

\section{Surface plot of viscosity vs A and B}

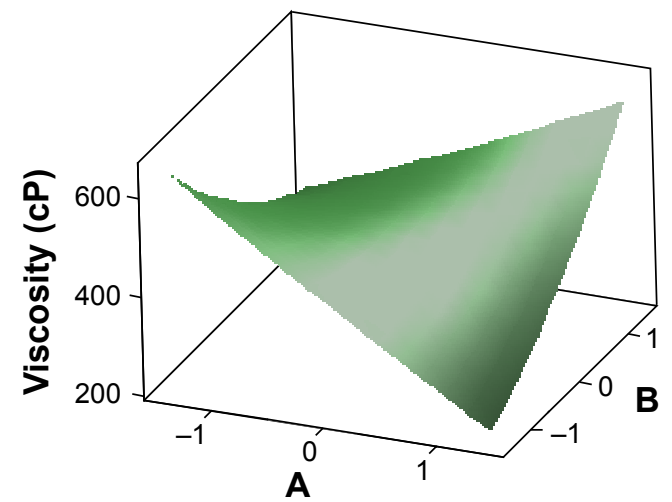

Figure 2 Response surface plot showing the influence of PG and OO on viscosity of formulation.

Note: $X_{1}=\mathrm{A}=\mathrm{PG}$ and $X_{2}=\mathrm{B}=\mathrm{OO}$.

Abbreviations: PG, propylene glycol; OO, olive oil. 


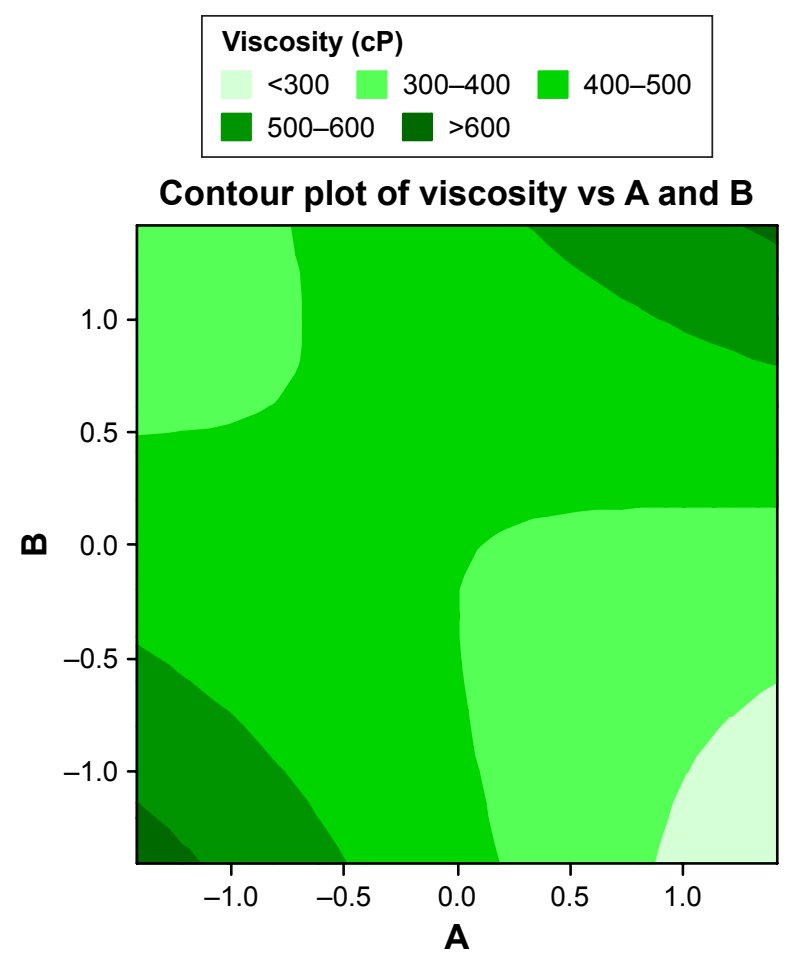

Figure 3 Contour plot showing the influence of PG and $O O$ on viscosity of formulation.

Note: $X_{1}=A=P G$ and $X_{2}=B=O O$.

Abbreviations: PG, propylene glycol; OO, olive oil. irritancy. Many of the psoralens produce irritation when used topically; therefore, the counter irritant/anti-inflammatory steroids like betamethasone relieved the subjects. ${ }^{28}$

\section{Visual survey}

A few days after application of the ointment on white lesions of skin, positive changes were observed. White patches became reddish/well vascularized. The healing process of the white patches was much similar to the healing of a wound. Patches became a little bit hard, and from their edges, the growth of normal pigmented skin was observable. With the passage of time, this pigmentation (darker than the normal skin) gradually covered the whole patch, and ultimately, the white patch disappeared with its evident conversion into dark pigmented matter. This pigmentation developed gradually toward central converging point with a decrease in the diameter of white patch from the corner to center. The whole phenomenon of pigmentation occurred within 12 weeks or sooner from the date of first application of the ointment. Treatment was stopped to let the comparatively darker spot to acquire the color of the surrounding normal skin. The desired normalization of the skin was seen in 4 weeks post stoppage of ointment therapy. In the follow-up

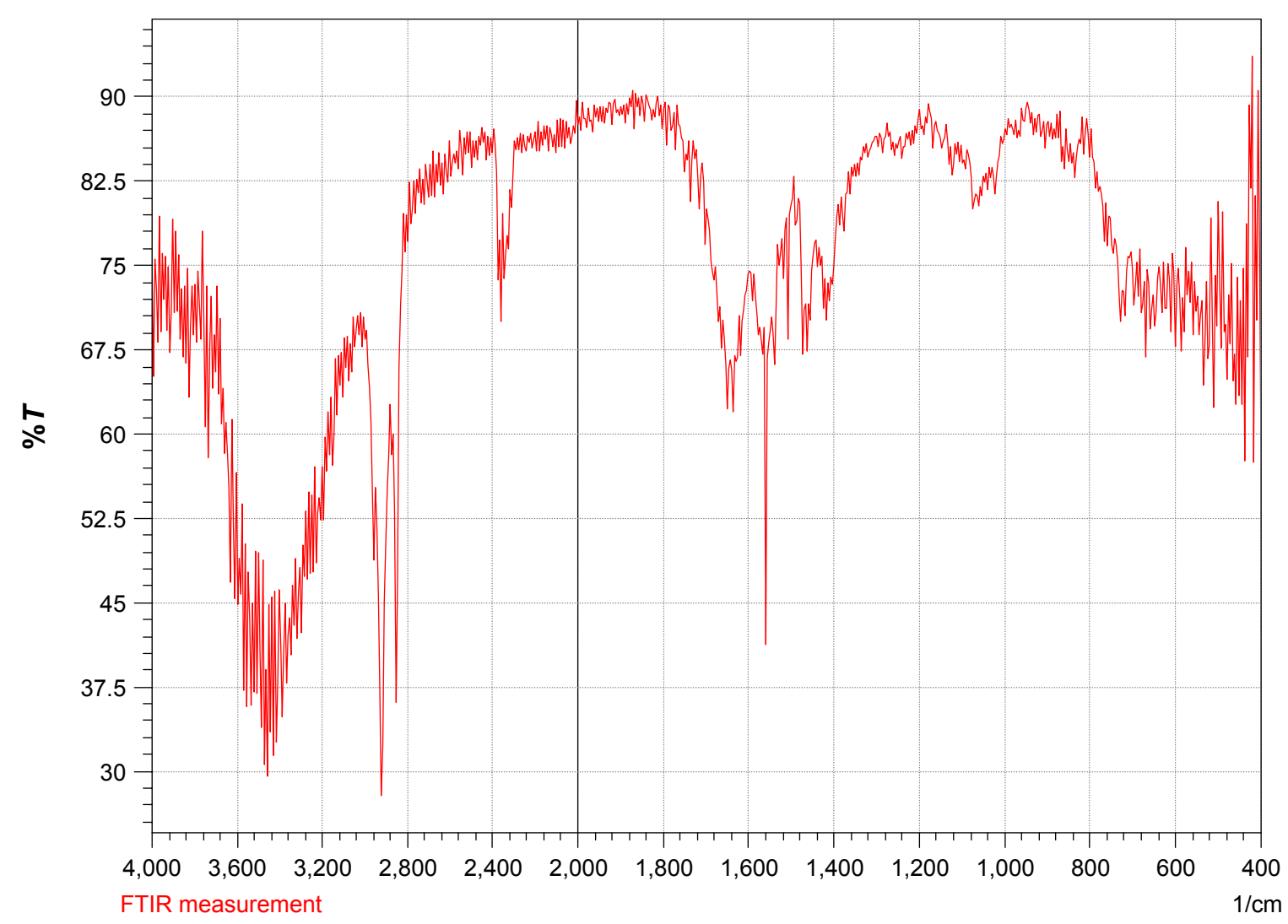

Figure 4 FTIR spectrum of powdered form of PC.

Abbreviations: FTIR, Fourier transform infrared spectroscopy; PC, Psoralea corylifolia. 


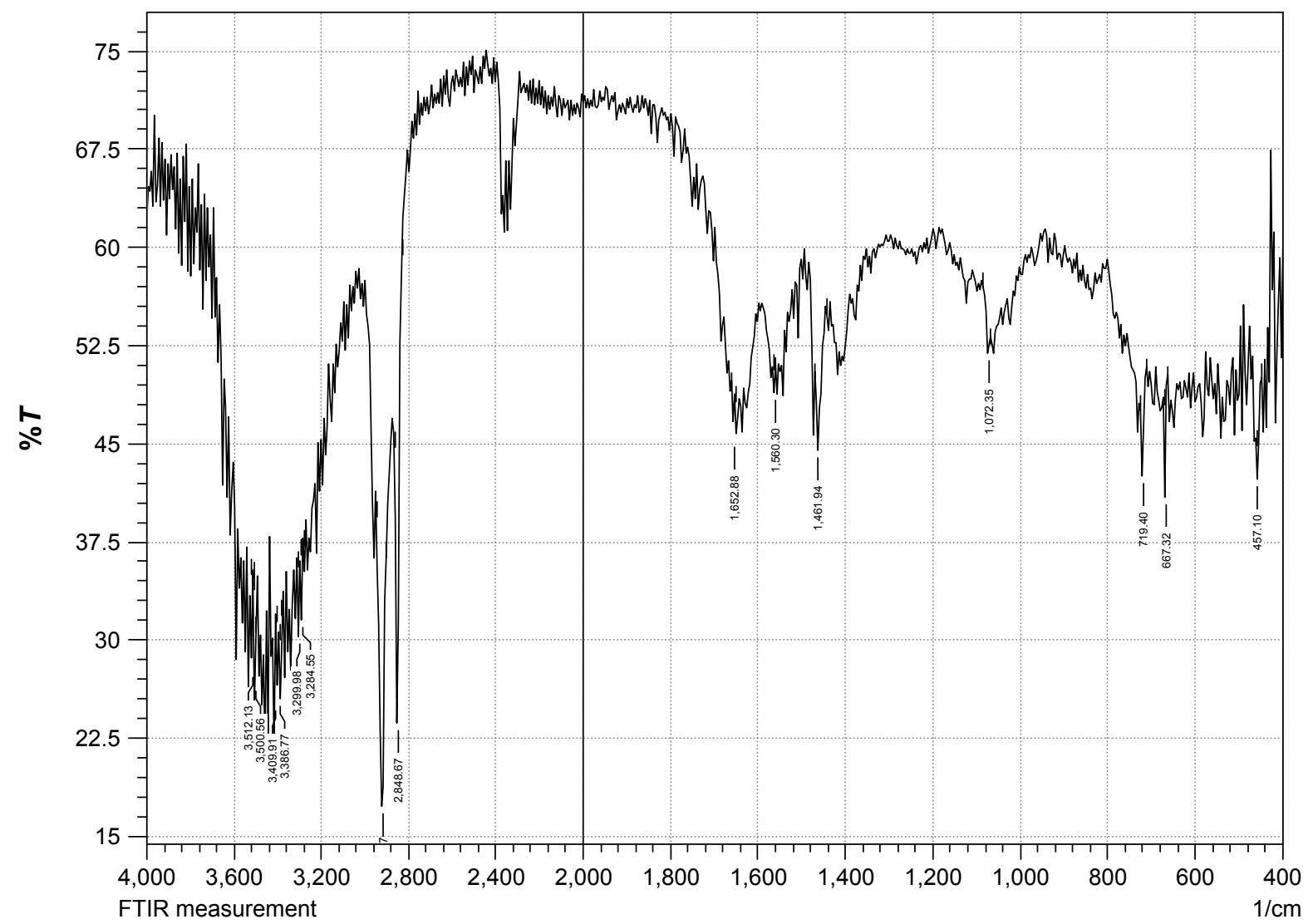

Figure 5 FTIR spectrum of formulation containing PC seed powder.

Abbreviations: FTIR, Fourier transform infrared spectroscopy; PC, Psoralea corylifolia.

phase, after 3 months of the trial completion, the recovered skin of the patient remained normal (without any relapse). The photographs of the recovery process of these small circular patches are given in Figure 6A-C. Dr Kanny Loll Dey strongly recommended the oleoresinous extract of the seeds of PC diluted with sample unguents as an application in leucoderma of vitiligo. He stated:

After application for some days the white patches appeared to become red and vascular; sometimes a slightly painful sensation was felt. Occasionally some small vesicles or pimples appear, and if these were allowed to remain undisturbed, they dry up, leaving a dark spot of pigmentary matter, which formed as it was a nucleus. From this point as well as the margin of the patch, pigmentary matter gradually developed which ultimately coalesced with each other and thus the whole patch disappeared. It was also remarkable that the appearance of fresh patch was arrested by its application. ${ }^{29}$

Some other observers, however, came up with only negative results by this mode of treatment. ${ }^{29}$ Melanoblasts are stimulated with the extract of PC. The extract is often used in the management of vitiligo ${ }^{30} \mathrm{PC}$ has been used in vitiligo by ayurvedic, unani and allopathic modes of treatment. ${ }^{31}$ Furanocoumarins (constituent of PC) yield psoralens and promote pigmentation. Powder of the babchi seed is used internally and externally (paste and ointment) as a remedy for leucoderma of vitiligo. ${ }^{32} \mathrm{PC}$ has been used in several traditional medicines and possesses antioxidant, antifungal, anti-inflammatory, antibacterial, antitumor and immunomodulatory activities. It contains a broad range of constituents, including isopsoralen, psoralen, psoralidin, flavones, bavachinin, bakuchiol, bakuchalcone, volatile oils and lipids, derived from different parts of plant. ${ }^{33}$ The drug is believed to have a local arterial action on capillary plexuses, dilating and increasing the plasma at the specific site. The skin becomes reddish, and pigment-producing melanobasts are stimulated. Stimulation of the exhausted melanoblasts enables them to exude pigment that penetrates in the white lesions of vitiligo skin. ${ }^{34}$ Repigmentation of vitiliginous lesions by the topical use of PC extract when combined with sun rays was known in ancient ages. 
A
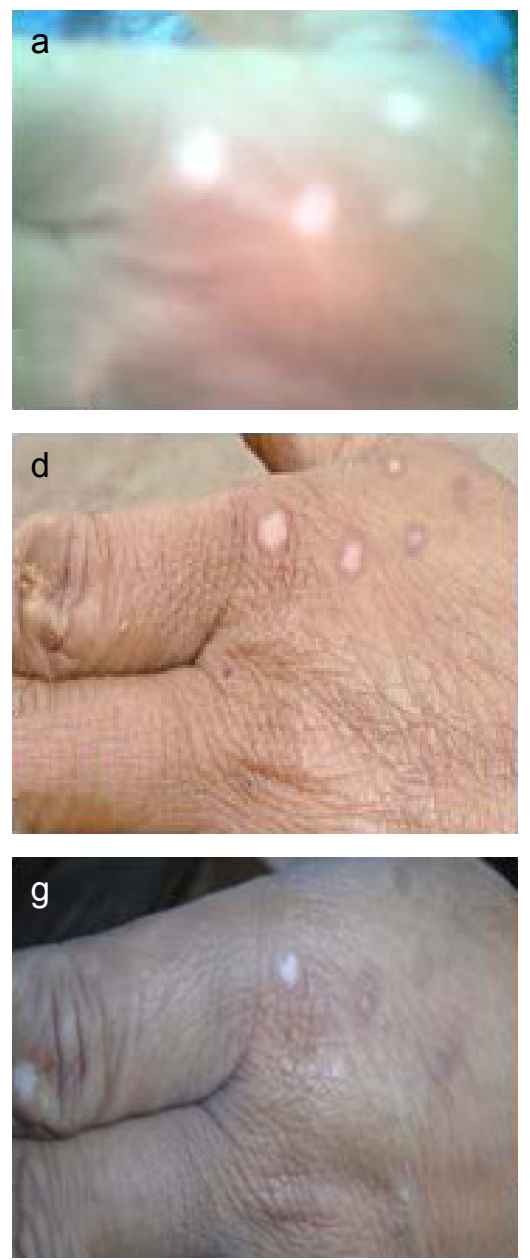

B

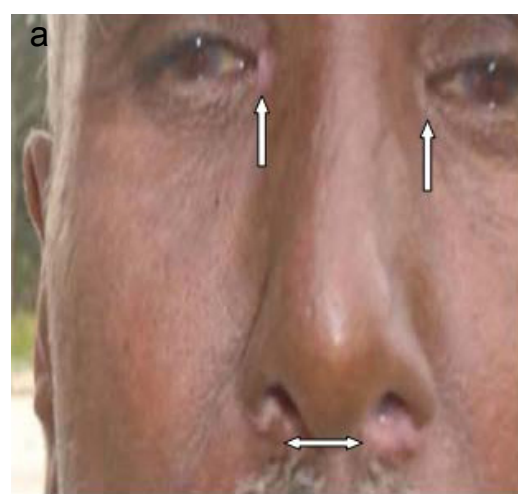

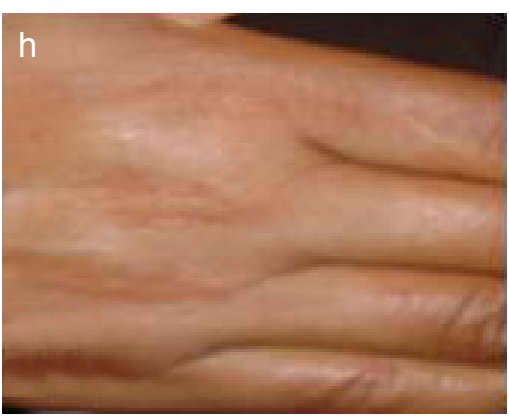

a2
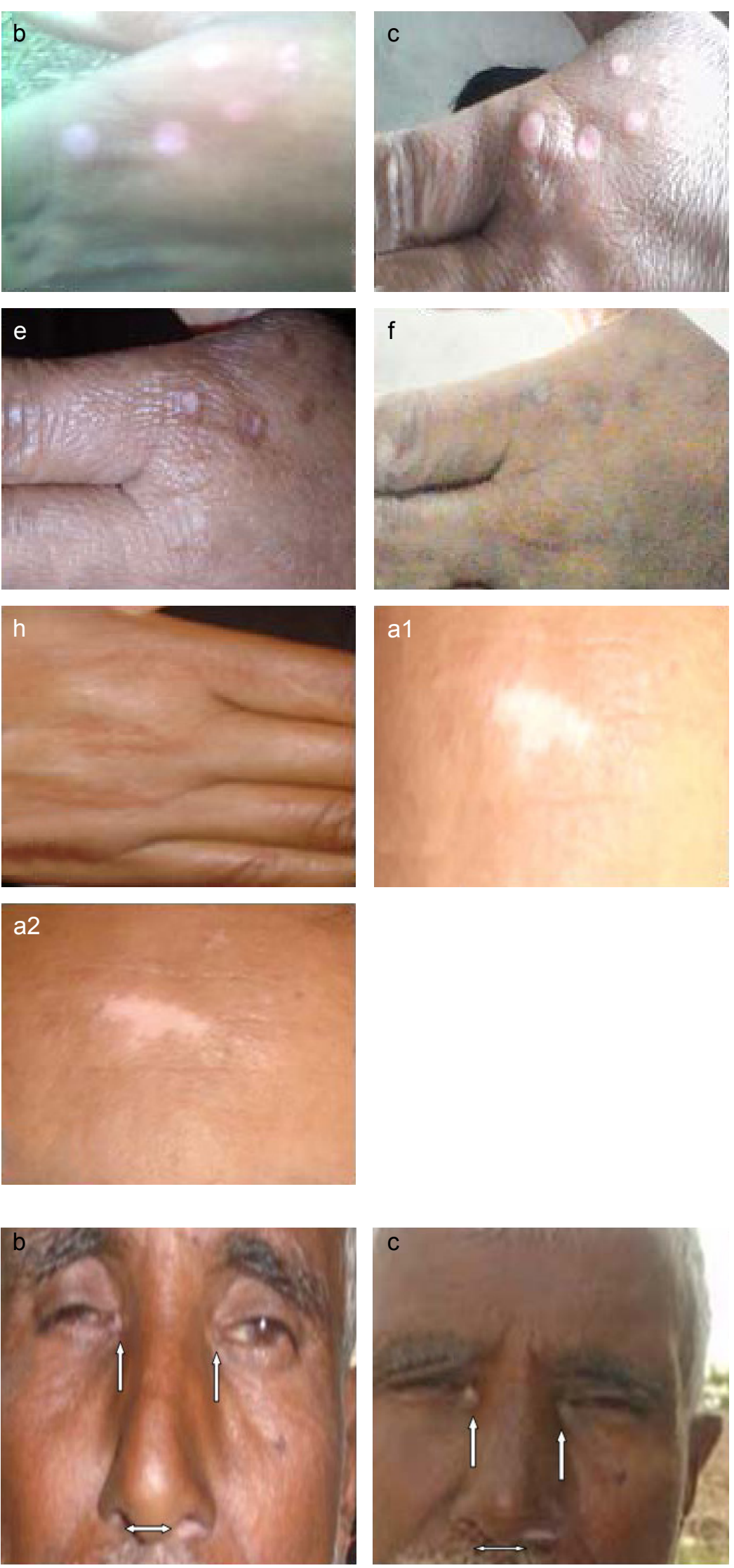

Figure 6 (Continued) 

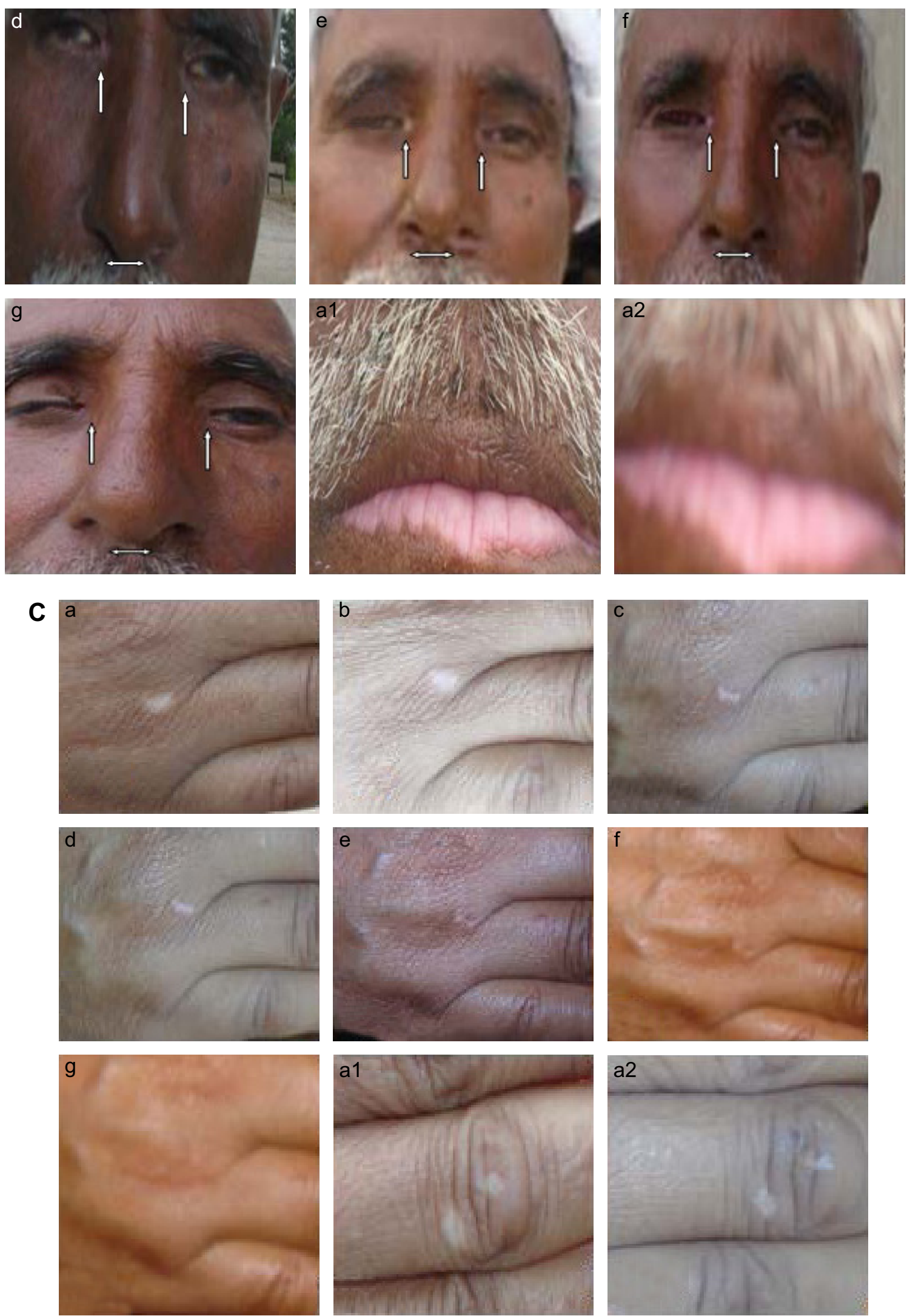

Figure 6 (A-C) Evolution of pigmentation.

Notes: Arrows were pointed toward the small circular white spots to elaborate the stepwise pigmentation of skin. (a) Before start of treatment; (b) after 12 days of start of treatment; (c) after 24 days of start of treatment; (d) after 36 days of start of treatment; (e) after 48 days of start of treatment; (f) after 60 days of start of treatment; (g) after 72 days of start of treatment; (h) small circular white patches of vitiligo into normal skin within 12 weeks of treatment; (al) self-control before start of treatment; (a2) self-control after completion of treatment period. 
Vitiliginous lesion of skin lacked melanocytes, while melanocytes existed in both normal and repigmented skin of same patients. By UV radiotherapy, there was a transfer of pigment from melanocytes to epithelium. Therefore, a successful vitiligo therapy must rely on either escalation of normal melanocytes within vitiliginous lesion or inward movement and expansion of melanocytes from perilesional skin, as well as the capability of epithelial cells to attain pigment from functional melanocytes. ${ }^{35}$ For $>3,000$ years, it has been believed that medicinal plants, particularly PC, in combination with natural sunrays can be employed with success to treat vitiligo. Photochemotherapy of psoralen is still the most effective current anti-vitiligo remedy. ${ }^{2}$

\section{Conclusion}

From the abovementioned results and discussion, it is concluded that the agreement between the measured in vivo evaluations and those of visual surveys indicated that the seed powder of PC exhibits proven efficacy in comparison to control in pigmenting the white patches of vitiligo skin on the patient's forearm and face. Despite the more risky and more expensive multiple regimens involving oral administration, there is demand for topical natural remedies that are safer, economical and efficacious as monotherapy. Therefore, PC offers a possible solution to the problem of small circular white lesions of vitiligo.

\section{Acknowledgments}

The authors would like to thank Higher Education Commission of Pakistan for the financial support, Prof Dr Hakim Ali Abro (Director Research, SMBBMU, Larkana, Pakistan) for facilitating the research, Dr Atif Akbar (BZU, Multan, Pakistan) for his help in the application of statistics and Dr Naeem Mubarak (LMDC, Lahore, Pakistan) and Dr Farid Menaa (Director, Fluorotronics, USA) for assisting in the revision process of this submission.

\section{Disclosure}

The authors declare no conflicts of interest in this research work.

\section{References}

1. Khandalavala BN, Nirmalraj MC. Rapid partial repigmentation of vitiligo in a young female adult with a gluten-free diet. Clin Dermatol. 2014;6(3):283-287.

2. Ortonne J-P. Psoralen therapy in vitiligo. Clin Dermatol. 1989; $7(2): 120-135$.

3. Bystryn J-C. Serum antibodies in vitiligo patients. Clin Dermatol. 1989; 7(2):136-145.

4. Bhandarkar SS, Kundu RV. Quality-of-life issues in vitiligo. Dermatol Clin. 2012;30(2):255-268.
5. Prignano F, Pescitelli L, Becatti M, et al. Ultrastructural and functional alterations of mitochondria in perilesional vitiligo skin. J Dermatol Sci. 2009;54(3):157-167.

6. Becatti M, Fiorillo C, Barygina V, et al. SIRT1 regulates MAPK pathways in vitiligo skin: insight into the molecular pathways of cell survival. J Cell Mol Med. 2014;18(3):514-529.

7. Barygina V, Becatti M, Lotti T, Moretti S, Taddei N, Fiorillo C. Treatment with low-dose cytokines reduces oxidative-mediated injury in perilesional keratinocytes from vitiligo skin. J Dermatol Sci. 2015;79(2):163-170.

8. Rezaei N, Gavalas NG, Weetman AP, Kemp EH. Autoimmunity as an aetiological factor in vitiligo. $J$ Eur Acad Dermatol Venereol. 2007; 21(7):865-876.

9. Oiso N, Suzuki T, Wataya-Kaneda M, et al. Guidelines for the diagnosis and treatment of vitiligo in Japan. J Dermatol. 2013;40(5):344-354.

10. Uikey SK, Yadav AS, Sharma AK, et al. The botany, chemistry, pharmacological and therapeutic application of Psoralea corylifolia $\mathrm{L}$. A Review. Int J Phytomed. 2010;2:100-107.

11. Khushboo PS, Jadhav VM, Kadam VJ, Sathe NS. Psoralea corylifolia Linn. - "Kushtanashini". Pharmacogn Rev. 2010;4(7):69-76.

12. Song A, Zhang J, Lebrilla CB, Lam KS. Solid-phase synthesis and spectral properties of 2-alkylthio-6H-pyrano[2,3-f]benzimidazole6-ones: a combinatorial approach for 2-alkylthioimidazocoumarins. J Comb Chem. 2004;6(4):604-610.

13. Fitzpatrick TB, Pathak MA. Basic considerations of the Psoralens: historical impact of methoxsalen and other furocoumarins. $J$ Invest Dermatol. 1959;32:223-229.

14. Yin S, Fan CQ, Wang Y, Dong L, Yue JM. Antibacterial prenylflavone derivatives from Psoralea corylifolia, and their structure-activity relationship study. Bioorg Med Chem. 2004;12(16):4387-4392.

15. Vayalil PK, Elmets CA, Katiyar SK. Treatment of green tea polyphenols in hydrophilic cream prevents UVB-induced oxidation of lipids and proteins, depletion of antioxidant enzymes and phosphorylation of MAPK proteins in SKH-1 hairless mouse skin. Carcinogenesis. 2003;24(5):927-936.

16. Evans WC. Trease and Evans Pharmacognosy. 15th ed. Elsevier: 2002. 2005:333.

17. Kar A. Pharmacognosy and Pharmacobiotechnology. 2nd ed. 2007:172.

18. The United States Pharmacopeia. 32nd ed. 2009:3131.

19. Shahzad Y, Afreen U, Nisar Hussain Shah S, Hussain T. Applying response surface methodology to optimize nimesulide permeation from topical formulation. Pharm Dev Technol. 2013;18(6):1391.

20. Akash MSH, Iqbal F, Raza M, et al. Characterization of ethylcellulose and hydroxypropyl methylcellulose microspheres for controlled of flurbiprofen. J Pharm Drug Deliv Res. 2013;2(1):1-10.

21. Natta R, Somsac T, Wisutidda T, et al. Narrow-band ultraviolet B radiation therapy for recalcitrant vitiligo in Asians. $J$ Am Acad Dermatol. 2003;49:472-476.

22. Louis TA, Lavori PW, Bailar JC 3rd, Polansky M. Crossover and selfcontrolled designs in clinical research. $N$ Engl J Med. 1984;310(1): 24-31.

23. Rafiq Khan M, Ranjini R. Preliminary phytochemical screening of seeds of Psoralea corylifolia. Int Res J Pharm. 2013;4(1):129-130.

24. Montenegro L, Rapisarda L, Ministeri C, Puglisi G. Effects of lipids and emulsifiers on the physicochemical and sensory properties of cosmetic emulsions containing vitamin E. Cosmetics. 2015;2:35-47.

25. Shah SN, Asghar S, Choudhry MA, Akash MS, ur Rehman N, Baksh S. Formulation and evaluation of natural gum-based sustained release matrix tablets of flurbiprofen using response surface methodology. Drug Dev Ind Pharm. 2009;35(12):1470-1478.

26. Paradkar A, Maheshwari M, Tyagi AK, Chauhan B, Kadam SS. Preparation and characterization of flurbiprofen beads by melt solidification technique. AAPS PharmSciTech. 2003;4(4):1-9.

27. Khatune NA, Islam ME, Haque ME, Khondkar P, Rahman MM. Antibacterial compounds from the seeds of Psoralea corylifolia. Fitoterapia. 2004;75(2):228-230. 
28. Sanclemente G, Garcia JJ, Zuleta JJ, Diehl C, Correa C, Falabella R. A double-blind, randomized trial of $0.05 \%$ betamethasone vs. topical catalase/dismutase superoxide in vitiligo. J Eur Acad Dermatol Venerol. 2008;22(11):1359-1364.

29. Said HM. Hamdard pharmacographica. Indica. 1972;XV(Special Issue): $412-413$.

30. Senthilkumar U, Mohanram A. Allopathic and ayurvedic approaches in management of vitiligo. FASEB J. 2013;27:890-893.

31. Chopra RN, Chopra IC. Indigenous Drugs of India. Kolkata. 2nd ed. Academic Publishers; 1958:391.
32. Panda H. Herbs, Cultivation and Medicinal Uses. New Delhi: National Institute of Industrial Research; 2000:479-481.

33. Chopra B, Dhingra AK, Dhar KL. Psoralea corylifolia L. (Buguchi) folklore to modern evidence: review. Fitoterapia. 2013;90:44-56.

34. William B. New Manual of Homeopathic Materia Medica and Repertory. 9th ed. New Delhi: B. Jain Publishers Pvt. Ltd; 2002:11-29.

35. Spritz RA. The genetics of vitiligo. J Invest Dermatol. 2011;131: E18-E20.

\section{Publish your work in this journal}

Drug Design, Development and Therapy is an international, peerreviewed open-access journal that spans the spectrum of drug design and development through to clinical applications. Clinical outcomes, patient safety, and programs for the development and effective, safe, and sustained use of medicines are the features of the journal, which has also been accepted for indexing on PubMed Central. The manuscript management system is completely online and includes a very quick and fair peer-review system, which is all easy to use. Visit http://www.dovepress.com/testimonials.php to read real quotes from published authors.

Submit your manuscript here: http://www.dovepress.com/drug-design-development-and-therapy-journal 